\title{
Effect of peak expiratory flow data quantity on diagnostic sensitivity and specificity in occupational asthma
}

\author{
W. Anees, P.F. Gannon, V. Huggins, C.F.A. Pantin, P.S. Burge
}

Effect of peak expiratory flow data quantity on diagnostic sensitivity and specificity in occupational asthma. W. Anees, P.F. Gannon, V. Huggins, C.F.A. Pantin, P.S. Burge. (C) ERS Journals Ltd 2004.

ABSTRACT: Serial peak expiratory flow records are recommended in the first-line investigation of suspected occupational asthma.

The effects of sequentially reducing the numbers of working weeks, consecutive days at work and readings taken per day on diagnostic sensitivity and specificity were investigated, using good quality peak expiratory flow records from 81 workers with independently confirmed occupational asthma and 60 asthmatics without occupational exposure.

Sensitivity was $81.8 \%$ for records of 4 weeks' duration and $70 \%$ for those of 2 weeks' duration (specificity 93.8 and $82.4 \%$ respectively). The sensitivity fell to $56.7 \%$ if there were only 2 consecutive workdays in each work period. Although best at 8 readings $\cdot$ day $^{-1}$, sensitivity and specificity were acceptable with four daily readings $(82.4$ and $87 \%)$. The effect of defining a record as being of adequate quality if it was of $\geqslant 2.5$ weeks' duration, with $\geqslant 4$ readings $\cdot$ day $^{-1}$ and $\geqslant 3$ consecutive workdays in each work period, was tested in records not used in the initial data reduction process. The sensitivity and specificity respectively of adequate records were 78.1 and 91.8 versus 63.6 and $83.3 \%$ for inadequate records.

Peak expiratory flow records for the diagnosis of occupational asthma should be interpreted with caution if they do not satisfy the suggested minimum data quantity criteria.

Eur Respir J 2004; 23: 730-734.
Occupational Lung Disease Unit, Birmingham Heartlands Hospital, Birmingham, UK.

Correspondence: W. Anees, Occupational Lung Disease Unit, Birmingham Heartlands Hospital, Bordesley Green East, Birmingham, B9 5SS, UK.

Fax: 441217720292

E-mail: wasif@anees3.freeserve.co.uk

Keywords: Oasys-2

occupational asthma

peak expiratory flow

Received: December 302001

Accepted after revision: December 12003

This study was funded by the European Chemical Industry Council, Brussels, Belgium. $\mathrm{W}$. Anees is also supported by a grant from the Colt foundation, Havant, UK.
Serial self-measurement of peak expiratory flow (PEF) is recommended in the first-line investigation of workers with suspected occupational asthma [1]. This is both sensitive and specific [2-6]. It was originally suggested that PEF measurement should be performed every $2 \mathrm{~h}$ whilst awake for a minimum of 4 weeks, including periods at and away from work [3]. Recording measurements this frequently and for this duration of time requires a significant degree of motivation and cooperation from the subject. MALO et al. [7] suggested that four evenly spaced daily readings were adequate for diagnosing occupational asthma, with little loss of sensitivity compared to two-hourly readings. There is little published data as to whether keeping PEF records for a shorter duration of time adversely affects diagnostic sensitivity and specificity. Nor is it known whether diagnostic sensitivity and specificity are influenced by the number of consecutive days at work or at rest, which would be of particular relevance to shift workers.

The aim of the present study was to determine how PEF data quantity (i.e. record duration, number of daily readings and number of consecutive days at work or rest) influences the sensitivity and specificity of PEF records for diagnosing occupational asthma.

\section{Methods}

Good-quality PEF records from workers with definite occupational asthma were sequentially reduced by removing:
1) data from the end of the record, to study the effects of duration; 2) daily readings, to study the effect of number of daily readings; and 3) data for whole days, to study the effects of number of consecutive days at work or rest. At each stage of the reduction process, the record was re-evaluated for evidence of occupational effect and diagnostic sensitivity was determined for that amount of data. The same process was performed on records from workers who did not have current occupational asthma in order to determine specificity.

Identification of subjects with definite occupational asthma (gold-standard positive subjects)

Consecutive workers seen at the Birmingham Chest Clinic (Birmingham, UK) between 1993 and 2001 with a diagnosis of occupational asthma, confirmed independently of PEF records, were identified. The diagnosis was made on the basis of a clinical history suggestive of occupational asthma plus either: 1) positive specific inhalation challenge test results; 2) specific immunoglobulin E directed against an agent to which the subject was exposed and which was known to cause occupational asthma; or 3) a four-fold change in methacholine bronchial reactivity between periods with and without exposure. PEF records kept during the period of initial investigation, whilst the subject was exposed at work, were designated "gold-standard positive" records regardless of the quality or the result of the record. At the time of the investigation, all subjects had been requested to keep PEF 
records, recording the best of three readings every $2 \mathrm{~h}$ whilst awake at and away from work.

\section{Identification of subjects who did not have occupational asthma (gold-standard negative subjects)}

PEF records kept by subjects seen at the Birmingham Chest Clinic who were not at work were systematically identified since these subjects could not have occupational asthma. All had previously been diagnosed as having asthma (either occupational or nonoccupational) by a physician. All records comprised $\geqslant 4$ readings $\cdot$ day $^{-1}$ for $>2$ weeks. Although readings were taken whilst away from exposure to potential occupational sensitisers, Mondays to Fridays were artificially marked as workdays, with weekends being rest days. Differences in PEF indices between "rest" and "work" periods were therefore not as a result of genuine occupational exposure.

\section{Processing of peak expiratory flow records}

Periods with documented lower respiratory tract infections or major laze or learning effects were removed from records before processing. Records were linearised [8], plotted and scored using a computer program called Oasys-2 [9]. Oasys-2 employs discriminant analysis to compute a score in the range $1-4$, indicating the probability of occupational asthma. An Oasys- 2 score of $>2.5$ has been shown to have a sensitivity of $75 \%$ and specificity of $94 \%$ for diagnosing occupational asthma.
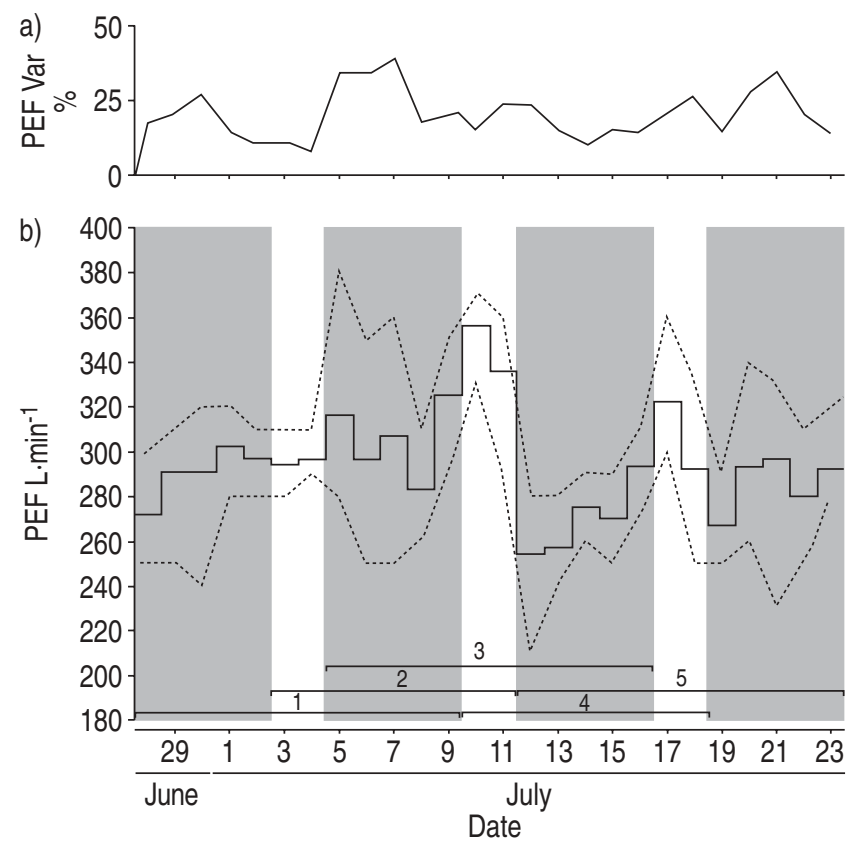

Fig. 1.-a) Diurnal variability of peak expiratory flow (PEF) and b) corresponding gold-standard positive PEF record ( - : mean daily PEF; ---: maximum/minimum daily PEF) showing 5 overlapping workrest-work and rest-work-rest complexes (numbered horizontal bars), each of 5 workday $(\square)$ and 2-rest-day ( $\square$ ) format. The whole-record Oasys-2 score was 2.88 (true positive). During the reduction process, sections of the record were removed sequentially, starting with the last work period: the Oasys- 2 score for complexes $1-4$ fell to 2.5 (false negative). The last rest period was removed next and the remainder of the record rescored. This was continued until only one work-rest-work complex remained. Var: variability.
Data reduction from good quality peak expiratory flow records

Duration of record. Good quality gold-standard positive PEF records were identified with: 1$) \geqslant 3$ readings $\cdot$ day $^{-1}$ for $\geqslant 75 \%$ of days; 2) 4-6 consecutive days in each work period; 3) 2-3 consecutive rest days in each rest period; and 4$) \geqslant 5$ work-restwork or rest-work-rest complexes in duration. An example of a record containing 5 overlapping complexes of 5-workday and 2-rest-day format is shown in figure 1 . In cases in which a subject had more than one PEF record, only the first good quality $\mathrm{PEF}$ record was used for data reduction. The reduction process involved removing the last work or rest period, such that there was one less complex. The shortened record was then rescored using Oasys-2. The number of complexes continued to be reduced until only one complex remained in each record. At each stage of the reduction process, a gold-standard positive record with a score of $>2.5$ was defined as a true positive; goldstandard positive records with an Oasys- 2 score of $\leqslant 2.5$ were defined as false negatives. The sensitivity for diagnosing occupational asthma for records of a particular complex length was calculated by determining the proportion of records of that duration that had Oasys- 2 scores of $>2.5$.

The same process was applied to the gold-standard negative PEF records to see whether records became falsely positive. At each stage of the reduction process, a gold-standard negative record with an Oasys- 2 score of $\leqslant 2.5$ was a true negative, and one with a score of $>2.5$ was a false positive. Specificity was calculated by determining the proportion of records of that duration that had Oasys- 2 scores of $\leqslant 2.5$.

Number of consecutive days at work and rest. The same goldstandard records identified for the duration reduction process above were used for reducing the number of consecutive days at work or rest. The last day at work in each work period was removed and the record rescored using Oasys-2. For example, the first step would be to remove a Friday from all work periods and then rescore the record. Thursdays would then be removed (fig. 2) and so on until only the Monday workday remained. This was also performed for rest days.

Number of daily readings. Gold-standard records were identified for data reduction with: 1$) \geqslant 8$ readings $\cdot$ day $^{-1}$ for $\geqslant 75 \%$ of days; 2) $\geqslant 3$ complexes' duration; and 3) no night shift periods. PEF readings were removed from each day until there were 4 readings $\cdot$ day $^{-1}$, corresponding as closely as possible to timings of 06:00, 12:00, 17:00 and 24:00 h. The 4-readings $\cdot$ day $^{-1}$ records were then rescored using Oasys-2. Further readings were removed until there were 2 readings $\cdot$ day $^{-1}$, as close as possible to times of $06: 00$ and 17:00 h, and the records rescored. Records were also reduced to single daily readings (either morning or evening).

\section{Definition of adequate and inadequate peak expiratory flow data quantity and reassessment of diagnostic sensitivity and specificity}

Criteria for the definition of adequacy of PEF data quantity were set according to the results of the data reduction process. The diagnostic sensitivity for adequate and inadequate PEF records was reassessed using goldstandard positive records that were not of good enough quality to have been used in the initial data reduction process. The specificity of records of adequate and inadequate data quantity was tested in all gold-standard negative records. 

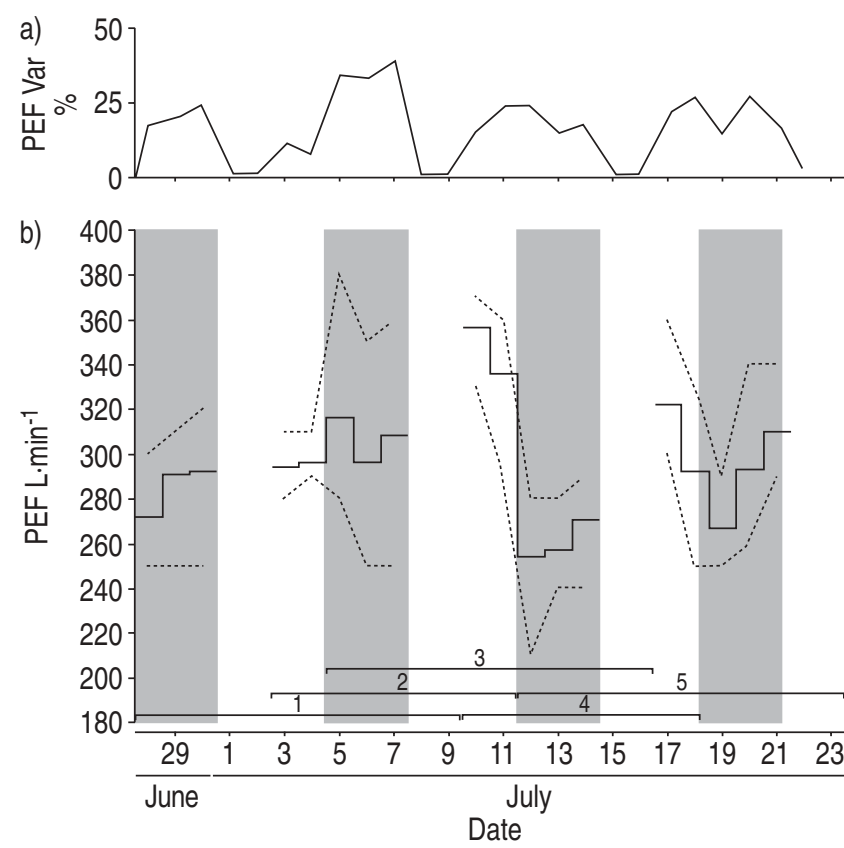

Fig. 2. -a) Diurnal variability of peak expiratory flow (PEF) and b) corresponding gold-standard positive PEF record (- : mean daily PEF; ---: maximum/minimum daily PEF) from figure 1 but with the data for Thursdays and Fridays (the last 2 workdays of each 5workday period) removed ( 0 readings $\cdot$ day $\left.^{-1}\right)$ such that there are 5 overlapping work-rest-work and rest-work-rest complexes (numbered horizontal bars), each of 3-workday ( $\square$ ) and 2-rest-day ( $\square$ ) format. The Oasys-2 score remained positive at 2.8. Each stage of the reduction process, from 4 down to 1 workdays (each with 2 rest days), was scored by Oasys-2 to determine the probability of occupational asthma for the relevant number of consecutive days at work. Var: variability.

\section{Results}

Gold-standard positive records (137) were identified from 81 workers with occupational asthma. Sixty gold-standard negative records were identified from subjects not occupationally exposed. The demographics of all gold-standard positive and negative subjects are shown in table 1 . The characteristics of gold-standard positive subjects according to whether the PEF record was positive or negative are shown in table 2 .

Table 1.-Demographics of gold-standard positive ${ }^{\#}$ and negative ${ }^{*}$ subjects

\begin{tabular}{|c|c|c|}
\hline & Positive & Negative \\
\hline Subjects $n$ & 81 & 60 \\
\hline Age yrs & $43.7 \pm 9.3$ & $49.1 \pm 11.4$ \\
\hline Males $\%$ & 62.9 & 73.2 \\
\hline Atopic $\%$ & 52.8 & 34.2 \\
\hline \multicolumn{3}{|l|}{ Smoking status $\%$} \\
\hline Current smoker & 13.5 & 22.5 \\
\hline Exsmoker & 32.4 & 35.0 \\
\hline Never smoker & 54.1 & 42.5 \\
\hline FEV1 \% pred & $86.9 \pm 20.7$ & $81.8 \pm 18$ \\
\hline FEV1/FVC & $72.9 \pm 16.6$ & $69.6 \pm 13.5$ \\
\hline On inhaled steroids ${ }^{+} \%$ & 68.2 & 89.7 \\
\hline
\end{tabular}

Data are presented as mean \pm SD unless otherwise indicated. FEV1: forced expiratory volume in one second; FVC: forced vital capacity; \% pred: per cent predicted. ${ }^{\#}$ : occupational asthma; ${ }^{\uparrow}$ : nonoccupational asthma; ${ }^{+}$: at time of record.
Table 2. - Characteristics of gold-standard positive subjects with positive ${ }^{\#}$ and negative peak expiratory flow (PEF) records ${ }^{+}$

\begin{tabular}{lcc}
\hline & Positive PEF & Negative PEF \\
\hline Subjects n & 101 & 36 \\
Males/females n & $72 / 29$ & $20 / 16$ \\
Gold-standard diagnostic test \% & & \\
$\quad$ Specific challenge test & 67.3 & 72.2 \\
4-fold change in reactivity & 8.9 & 8.3 \\
$\quad$ Specific IgE & 21.8 & 19.4 \\
On inhaled steroids \% & 69.6 & 61.9 \\
HMW agent cause of OA \% & 10.9 & 30.6 \\
Main cause of OA n & & \\
Metals & 21 & 7 \\
$\quad$ Latex & 16 & 6 \\
Biocides & & 3 \\
Flour & 11 & 5 \\
Isocyanates & 6 & 3 \\
Oil mists & 5 & \\
Colophony & 4 & \\
TGIC & 3 & \\
Chloramines & & \\
\hline
\end{tabular}

IgE: immunoglobulin E; HMW: high-molecular-weight; OA: occupational asthma; TGIC: triglycidyl isocyanurate. ${ }^{\#}$ : Oasys-2 score $>2.5 ;$; Oasys- 2 score $\leqslant 2.5 ;^{+}$: some subjects had more than one PEF record.

\section{Complex reduction}

Thirty good-quality gold-standard positive records and 34 gold-standard negative records underwent data reduction. Table 3 shows the effect of record duration on sensitivity and specificity. There was a slight increase in sensitivity with increasing record duration. Specificity was poor when records comprised $<3$ complexes ( $<2.5$ weeks' duration). However, specificity increased dramatically with record duration. Overall, records of 4 weeks' duration (i.e. 6 complexes) gave the highest combined sensitivity and specificity.

\section{Number of consecutive days at work and rest}

Thirty good-quality gold-standard positive records and 34 gold-standard negative records underwent data reduction. There was a marked drop in sensitivity if there were fewer than 3 consecutive days at work (table 4). Sensitivity was little affected when there was only 1 rest day compared to when there were 2 consecutive rest days. Specificity was not adversely affected by the number of consecutive work or rest days.

\section{Reduction of number of daily readings}

Thirty-four gold-standard positive and 23 gold-standard negative records underwent data reduction. Table 5 shows

Table 3. - Effect of record duration" on diagnostic sensitivity and specificity in occupational asthma

\begin{tabular}{lcccccc}
\hline & \multicolumn{6}{c}{ Complexes n } \\
\cline { 2 - 7 } & 1 & 2 & 3 & $4^{+}$ & 5 & $6^{\S}$ \\
\hline Sensitivity \% & 73.3 & 70.0 & 83.3 & 76.7 & 80.0 & 81.8 \\
Specificity \% & 64.7 & 82.4 & 88.2 & 94.1 & 91.2 & 93.8
\end{tabular}

\#: number of complexes; ${ }^{\circ}$ : $\sim 2$ weeks; ${ }^{+}$: $\sim 3$ weeks; ${ }^{\S}$ : $\sim 4$ weeks. 
Table 4.-Effect of number of consecutive days at work or rest on diagnostic sensitivity and specificity in occupational asthma

\begin{tabular}{lcccccc}
\hline & \multicolumn{5}{c}{ Pattern of work-rest-work days } \\
\cline { 2 - 7 } & $5-2-5$ & $4-2-4$ & $3-2-3$ & $2-2-2$ & $1-2-1$ & $5-1-5$ \\
\hline Sensitivity \% & 76.7 & 76.7 & 70.0 & 56.7 & 46.7 & 73.3 \\
Specificity \% & 90.0 & 90.0 & 90.0 & 100 & 90.0 & 90.0 \\
\hline
\end{tabular}

the effect of number of readings per day on diagnostic sensitivity and specificity. Sensitivity and specificity both fell with $<8$ readings $\cdot$ day $^{-1}$, although both were surprisingly good even with just 1 afternoon reading $\cdot \mathrm{day}^{-1}$.

Diagnostic sensitivity and specificity in peak expiratory flow records of adequate and inadequate data quantity

Although the sensitivity for diagnosing occupational asthma improved with increasing data quantity, for the sake of inclusiveness, a record was defined as being of adequate data quantity if it satisfied all of the following criteria: 1$) \geqslant 3$ complexes in duration; 2) $\geqslant 3$ consecutive days at work in each work period for $\geqslant 75 \%$ of work periods; and 3 ) $\geqslant 4$ readings $\cdot$ day $^{-1}$ for $\geqslant 75 \%$ of days.

The effect of these criteria on diagnostic sensitivity was tested in the remaining 74 gold-standard positive records that had not been used in data reduction, of which 41 were of adequate data quantity and 33 of inadequate data quantity. Of the gold-standard negative records, 48 were of adequate data quantity and 12 of inadequate data quantity. Results are shown in table 6.

\section{Discussion}

PEF data quantity appears to be an important determinant of diagnostic sensitivity and specificity in occupational asthma. Maximum sensitivity and specificity for diagnosing occupational asthma were obtained with records of 4 weeks'

Table 5. - Effect of number of daily peak expiratory flow (PEF) readings on diagnostic sensitivity and specificity in occupational asthma

\begin{tabular}{lcccccc}
\hline & \multicolumn{5}{c}{ Daily PEF readings n } \\
\cline { 2 - 7 } & 8 & 4 & 3 & 2 & $1^{\#}$ & $1^{\text {ฯ }}$ \\
\hline Sensitivity \% & 85.3 & 82.4 & 76.5 & 82.4 & 79.4 & 55.9 \\
Specificity \% & 95.7 & 87.0 & 87.0 & 82.6 & 87.0 & 73.9 \\
\hline
\end{tabular}

\#: 17:00 h; ${ }^{\bullet}: 06: 00 \mathrm{~h}$.

Table 6. - Diagnostic sensitivity and specificity in records of adequate and inadequate peak expiratory flow data quantity ${ }^{\#}$ in occupational asthma

\begin{tabular}{lcc}
\hline & Sensitivity $\%$ & Specificity \% \\
\hline $\begin{array}{l}\text { Adequate data quantity } \\
\text { Inadequate data quantity }\end{array}$ & 78.1 & 91.7 \\
\hline : an adequate record was one of $\geqslant 3$ complexes in duration, with $\geqslant 3$ \\
$\begin{array}{l}\text { consecutive days at work in each work period and } \geqslant 4 \text { readings } \text { day }^{-1} \text {. If } \\
\text { any of these criteria were not satisfied, the record was deemed to be of } \\
\text { inadequate data quantity. }\end{array}$
\end{tabular}

duration, 8 readings $\cdot$ day $^{-1}$ and $\geqslant 4$ consecutive days in each work period. However, few records satisfy these criteria in practice and the gain in terms of sensitivity and specificity is slight. More inclusive criteria for defining whether a PEF record is of adequate data quantity are that they are of $\geqslant 3$ complexes in duration (equivalent to 2.5 weeks), $\geqslant 4$ readings $\cdot$ day $^{-1}$ and $\geqslant 3$ consecutive days in each work period. The effect of defining adequacy of the PEF record according to these criteria was tested in PEF records of poorer quality than those used in the initial data reduction process; the sensitivity for records of adequate data quantity was $78.1 \%$, with a specificity of $91.8 \%$. Records that were of inadequate data quantity according to these criteria were less likely to show occupational asthma and were of lower specificity. It could even be suggested that $<4$ readings $\cdot$ day $^{-1}$ are required. However, 2 readings $\cdot$ day $^{-1}$ can cause underestimation of the true diurnal variation by up to $15 \%$ compared to $4 \%$ with 4 readings $\cdot$ day $^{-1}[10]$.

Consecutive subjects diagnosed as having occupational asthma by any of the generally accepted objective methods other than the PEF record itself were included as goldstandard positive subjects. In order to determine specificity, it was necessary to identify subjects who definitely did not have occupational asthma. Some studies have used subjects in whom a diagnosis of occupational asthma was excluded by specific bronchial challenge testing; however, the possibility of false-negative challenge test results remains (e.g. due to wrong agent, insufficient dose or inability to reproduce workplace conditions). Other studies have used asymptomatic individuals at low risk of occupational asthma as gold-standard negative subjects, e.g. Post Office workers [11]. Unfortunately, most occupational groups are exposed to potential sensitisers in their workplace, e.g. office workers exposed to toning agents from photocopying machines and floor cleaning agents or healthcare workers to latex. It is possible that even asymptomatic subjects could have occupational asthma (analogous to poor perceivers of asthma); hence, if their PEF records were to show work-related deterioration, these would wrongly be classified as falsely positive. In order to avoid these potential difficulties, PEF records from asthmatic subjects who were not at work (and hence could not have current occupational asthma) were used as gold-standard negative records. Even though there was no occupational exposure, Mondays to Fridays of these records were deliberately designated as workdays. Any record that had an Oasys-2 score of $>2.5$ would thus be a false positive. Despite no apparent occupational exposure, it is possible that these records could still show a genuine deterioration in PEF between Monday and Friday, e.g. due to undeclared work or a particular weekly pattern of activity such as heavy gardening work.

The method used to determine the effects of PEF data quantity involved sequentially reducing the data from goodquality PEF records from workers who definitely did or did not have occupational asthma. The Oasys-2 computer program was used to determine whether a PEF record at any particular stage of data reduction was positive. It is possible that, as the Oasys- 2 program shows less diagnostic sensitivity than an expert, the adverse effect on sensitivity of reducing data quantity would be less marked if the record were being scored by an expert. This could mean that, if an expert were available to interpret the record, less data than that suggested by the present study could be required for adequate interpretation.

Oasys-2 does have advantages over expert observers in that results are completely repeatable, and sensitivity and specificity are well described, whereas these would vary between experts. The results of a data reduction process depend on the nature of the PEF records selected. Workers with marked 
airflow obstruction occurring at work might require only a few readings at and away from work for their PEF record to suggest occupational asthma. Someone with less-marked airflow obstruction might require a greater quantity of data for the work effect to be evident, and, in such cases, removing data might diminish any notable work effect. In order to attempt to minimise selection bias, all available gold-standard positive records that were of high enough quality were used for data reduction. Indeed, several records were classified as positive but showing less-marked work-related deterioration (Oasys- 2 scores of $\geqslant 2.5$ but $<3$ ). These records did not show an increased tendency to become negative when the data was reduced.

Data reduction appears to be an appropriate technique for examining data quantity effects when the removed data has no influence on the remaining data, e.g. removing data from the end of a record or reducing the number of readings in a day. However, in cases in which consecutive days in a work or rest period are removed, the removed data influences the rest of the record. Caution must, therefore, be exercised when interpreting the effect of the number of consecutive work or rest days in a week. With the data set used in the present study, most cases of occupational asthma would have been identified using Oasys- 2 even if only 1 rest day had been present in each complex. However, the present authors would still recommend that, if the PEF is still significantly below the predicted value by the end of a rest period, monitoring for a longer period away from work is required.

In conclusion, the minimal acceptable standard of peak expiratory flow data quality for diagnosing occupational asthma is a record that is $\geqslant 3$ complexes in duration, with $\geqslant 4$ readings $\cdot$ day $^{-1}$ and $\geqslant 3$ consecutive days at work in each work period for the majority of the record. Diagnostic sensitivity and specificity are reduced if all of these criteria are not fulfilled, and such records should be interpreted with caution.

\section{References}

1. Moscato G, Godnic-Cvar J, Maestrelli P, Malo JL, Sherwood Burge P, Coifman R. Statement on self-monitoring of peak expiratory flows in the investigation of occupational asthma. Eur Respir J 1995; 8: 1605-1610.

2. Burge PS, $\mathrm{O}^{\prime}$ Brien I, Harries M. Peak flow rate records in the diagnosis of occupational asthma due to isocyanates. Thorax 1979; 34: 317-323.

3. Burge PS, $\mathrm{O}^{\prime}$ Brien I, Harries M. Peak flow rate records in the diagnosis of occupational asthma due to colophony. Thorax 1979; 34: 308-316.

4. Cote J, Kennedy SM, Chan-Yeung M. Sensitivity and specificity of PC20 and peak expiratory flow rate in cedar asthma. J Allergy Clin Immunol 1990; 85: 592-598.

5. Perrin B, Lagier F, L'Archevêque J, et al. Occupational asthma: validity of monitoring of peak expiratory flow rates and non-allergic bronchial responsiveness as compared to specific inhalation challenge. Eur Respir J 1992; 5: 40-48.

6. Leroyer C, Perfetti L, Trudeau C, L'Archevêque J, ChanYeung M, Malo J. Comparison of serial monitoring of peak expiratory flow and FEV1 in the diagnosis of occupational asthma. Am J Respir Crit Care Med 1998; 158: 827-832.

7. Malo J, Cote J, Cartier A, Boulet L, L'Archevêque J, Chan-Yeung M. How many times per day should peak expiratory flow rates be assessed when investigating occupational asthma? Thorax 1993; 48: 1211-1217.

8. Miller MR, Dickinson SA, Hitchings DJ. The accuracy of portable peak flow meters. Thorax 1992; 47: 904-909.

9. Burge PS, Pantin CF, Newton DT, et al. Development of an expert system for the interpretation of serial peak expiratory flow measurements in the diagnosis of occupational asthma. Occup Environ Med 1999; 56: 758-764.

10. Gannon PF, Newton DT, Pantin CF, Burge PS. Effect of the number of peak expiratory flow readings per day on the estimation of diurnal variation. Thorax 1998; 53: 790792.

11. Gannon PF, Newton DT, Belcher J, Pantin CF, Burge PS. Development of Oasys-2, a system for the analysis of serial measurements of peak expiratory flow in workers with suspected occupational asthma. Thorax 1996; 51: 484489.
Acknowledgements. The authors would like to thank all member of the Oasys-2 team (Birmingham, UK) for their help. 